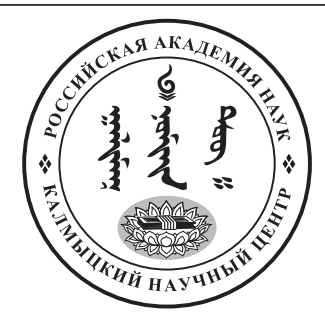

Published in the Russian Federation

Oriental Studies (Previous Name: Bulletin of the Kalmyk Institute

for Humanities of the Russian Academy of Sciences)

Has been issued as a journal since 2008

ISSN: 2619-0990; E-ISSN: 2619-1008

Vol. 13, Is. 5, pp. 1446-1455, 2020

DOI: $10.22162 / 2619-0990-2020-51-5-1446-1455$

Journal homepage: https://kigiran.elpub.ru

УДК 811.512 .37

DOI: $10.22162 / 2619-0990-2020-51-5-1446-1455$

\title{
О жанровом многообразии калмыцкой деловой письменности XVII-XIX вв.
}

\author{
Дарья Бадмаевна Гедеева
}

${ }^{1}$ Калмыцкий научный центр РАН (д. 8, ул. И. К. Илишкина, 358000 Элиста, Российская Федерация) кандидат филологических наук, ведущий научный сотрудник

iD 0000-0002-8735-9184. E-mail: dgedeeva@mail.ru

\author{
(C) КалмНЦ РАН, 2020 \\ (С) Гедеева Д. Б., 2020
}

Аннотация. Введение. Калмыки - один из немногих народов России, имеющих уже немало столетий свою национальную письменность. Духовная культура народа зафиксирована в многочисленных оригинальных и переводных текстах, представляющих собой философские сочинения, медицинские трактаты, исторические летописи, грамматические очерки, дневники буддийских паломников, художественные произведения, записи фольклорного материала и др. Калмыцкое вертикальное письмо использовалось также и в сфере делопроизводства. Начиная с XVII в., находясь на территории Нижнего Поволжья, в ходе дипломатических, военных, экономических отношений с Россией калмыки осваивали систему правил российского делопроизводства, сохраняя при этом свои традиции письменного делового языка. Архивные материалы свидетельствуют о жанровом многообразии калмыцкого делового письма того времени. В этой связи актуальнылми являются проблемы выявления и изучения жанровых образцов, составления их классификации, определения структурных, стилевых, языковых особенностей. Цель данной статьи - описание содержания и структуры выявленных жанровых разновидностей. Материалом исследования послужили документы из фондов Национального архива Республики Калмыкия. Bblводы. Полученные на данный момент результаты исследования свидетельствуют о том, что у калмыков в XVII-XIX вв. действительно функционировала деловая письменность со свойственным ей жанровым многообразием. Поэтому введение нами в научный оборот понятий «калмыцкая деловая письменность», «жанры калмыцкой деловой письменности» является обоснованным и необходимым. В зависимости от функциональной направленности выделены следующие жанры калмыцкой деловой письменности: cājiyin bičiq, zarčim (иаажчин бичг) 'правовые уложения’, amur yabuxu bičiq (амр йовх бичг) ‘увольнительное

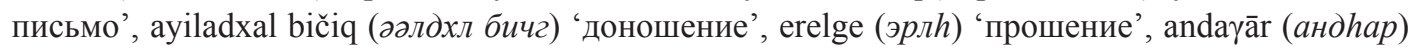
'присяга', tō (mo) 'реестр' и самый многочисленный bičiq (бичг) 'эпистолярий'. Еще не до конца изучены все значения названий документов bičiq tamaүa (бичг тамh) 'письмо-печать', 
elči bičiq (элч бичг) ‘письмо с нарочным’, zarliq (зәрлг) ‘указ; приказ’ и др. В этой связи изучение памятников калмыцкой деловой письменности является одним из приоритетных направлений монголоведения. Архивные материалы находятся в стадии выявления и не все изучены по причине их многочисленности, поэтому предложенный в статье жанровый состав деловых документов не окончателен и по мере изучения материала будет расширяться и уточняться.

Ключевые слова: калмыцкая деловая письменность, деловые документы, архив, жанр, правовые уложения, прошение, доношение, увольнительное письмо, присяга, реестр, эпистолярий Благодарность. Исследование проведено в рамках государственной субсидии - проект «Устное и письменное наследие монгольских народов России, Монголии и Китая: трансграничные традиции и взаимодействия» (номер госрегистрации: АААА-А19-119011490036-1).

Для цитирования: Гедеева Д. Б. О жанровом многообразии калмыцкой деловой письменности // Oriental Studies 2020. T. 13. № 5. C. 1446-1455. DOI: 10.22162/2619-0990-2020-51-5-1446-1455

UDC 811.512 .37

DOI: $10.22162 / 2619-0990-2020-51-5-1446-1455$

\title{
Kalmyk Official Writing, $17^{\text {th }}-19^{\text {th }}$ Centuries: Genre Diversity Revisited
}

\author{
Daria B. Gedeeva ${ }^{1}$
}

${ }^{1}$ Kalmyk Scientific Center of the RAS (8, Ilishkin St., Elista 358000, Russian Federation) Cand. Sc. (Philology), Leading Research Associate

iD 0000-0002-8735-9184. E-mail: dgedeeva@mail.ru

(C) KalmSC RAS, 2020

(C) Gedeeva D. B., 2020

\begin{abstract}
Introduction. The Kalmyks are one of the few peoples in Russia to have developed a script system of their own centuries ago. Spiritual culture of the ethnos can be traced in numerous original and translated texts of philosophical treatises, medical writings, historical chronicles, grammar essays, diaries of Buddhist pilgrims, fiction, recorded folklore materials, etc. The Kalmyk vertical script was also used for official writing. From the $17^{\text {th }}$ century onwards, in the Lower Volga Kalmyks would expand their knowledge of Russian record keeping procedures (in diplomatic, military and economic contacts), however, adhering to their own writing traditions. Archival materials available attest to that the then genres of Kalmyk official writing were diverse enough, which makes it essential to reveal and investigate some authentic genre samples, classify the latter, identifying certain structural, stylistic, and language features. Goals. So, the paper seeks to essentially and structurally describe the revealed genres. Materials. The work analyzes documents stored by the National Archive of Kalmykia. Conclusions. Current research results indicate in the $17^{\text {th }}-19^{\text {th }}$ centuries the Kalmyks did possess a comprehensive official writing system characterized by genre diversity, which makes the introduction of the terms 'Kalmyk official writing' and 'genre of Kalmyk official writing' reasonable and necessary. The study delineates a number of functional genres, such as cājiyin bičiq, zarčim (Cyrillic ияажсин бичг) 'codes, regulations', aтиг уаbихи bičiq (Cyr. амр йовх бичг) 'letter of discharge', ayiladxal bičiq (Cуr. әәлдхл бичг) 'report, dispatch', erelge (Cyr. эрлh) 'petition', andaүār (Cyr. андhap) 'vow', tō (Cyr. mo) 'register', and the vastest one - bičiq (Cyr. бичг) 'epistolary

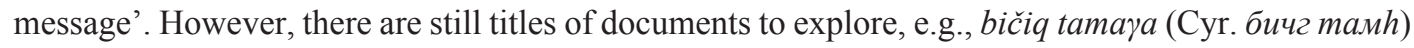
'letter-seal', elči bičiq (Cyr. элч бичг) 'letter (to be delivered by) a special messenger', zarliq (Cyr. зәрлг) 'order; decree', etc. In this context, further research of Kalmyk official writing documents can be a priority focus of Mongolian studies. Archival sources are only being discovered, and have not been studied due to large numbers. Thus, the genre structure presented is incomplete and shall definitely be revised or extended.
\end{abstract}


Keywords: Kalmyk official writing, official documents, archives, genre, codes, petition, report, letter of discharge, vow, register, epistolary

Acknowledgements. The reported study was funded by government subsidy — project name 'Oral and Written Heritage of Mongolic Peoples of Russia, Mongolia and China: Cross-Border Traditions and Interactions' (state reg. no. AAAA-A19-119011490036-1).

For citation: Gedeeva D. B. Kalmyk Official Writing, $17^{\text {th }}-19^{\text {th }}$ Centuries: Genre Diversity Revisited. Oriental Studies. 2020. Vol. 13(5): 1446-1455. DOI: 10.22162/2619-0990-2020-51-5-1446-1455

\section{Введение}

До настоящего времени исследователями, изучавшими язык калмыцких архивных текстов XVIII в., не был определен жанровый состав делового письма. Учеными был выявлен и рассмотрен лишь эпистолярий жанр деловой переписки, который содержал письма калмыцких ханов и князей, адресованные астраханской администрации в начале XVIII в. Написан ряд статей и монографий, посвященных лексико-грамматическим особенностям писем периода 1713-1734 гг. [Сусеева 2003; Кокшаева 2011; Бембеев, Асирова 2009].

Данные исследования внесли определенный вклад в изучение истории развития калмыцкого языка, предоставили широкому кругу языковедов транслитерацию и перевод труднодоступного для чтения лингвистического материала, определили грамматический строй калмыцкого языка начала XVIII в.

Для выявления жанрового состава калмыцкой деловой письменности необходимо расширить хронологические рамки исследования XVII-XIX вв., периодом функционирования делопроизводственной документации на калмыцком языке.

В данной статье мы даем описание выявленного нами жанрового состава калмыцких документов. Дальнейшее изучение архивного материала позволит создать более детальную их лингвистическую классификацию.

Изученный нами материал свидетельствует о том, что направленные калмыками официальным лицам и учреждениям российской администрации документы имеют многожанровый характер, составлены по всем правилам российского делопроизводства, хотя и написаны на калмыцком язы- ке с сохранением традиций калмыцкого письменного этикета. Разновидности документов отличаются характерными для них задачами, структурой, реквизитами, набором речевых штампов. Поэтому в данном исследовании мы используем такие понятия, как «калмыцкая деловая письменность XVII-XIX вв.» и «жанры калмыцкой деловой письменности», несущие характеристики как документов русского делопроизводства, так и традиций калмыцкого делового общения.

В настоящее время архивные документы этого периода исследователями воспринимаются как большой однородный массив деловых писем, написанных старым калмыцким письмом, трудным для прочтения и понимания. В этой связи введение их в научный оборот с историческим и лингвистическим описанием представляется нам весьма актуальной научной проблемой. Транслитерация текстов, переложение на современный калмыцкий язык, переложение русских переводов того периода, сопровождавших калмыцкие письма, на современный русский язык - все это даст тот богатый лингвистический материал, который крайне необходим исследователям истории языка.

\section{Общие замечания}

Изучая вопрос о жанрах калмыцкой деловой письменности, необходимо обратиться к исследованиям русского делового письма, оказавшего влияние на калмыцкое деловое письмо. Исследования русского языка в данной области были начаты давно, более двух веков назад. Написаны многочисленные труды, посвященные как центральной, так и региональной деловой письменности [Буслаев 1858; Соколова 1957; Филин 1974]. 
Эти исследования продолжаются успешно и в наши дни [Гауч 2013; Никитин 2016; Городилова 2018; Попов 2017; Майоров 2019]. Так, учеными продолжает составляться и уточняться классификация документов, которые в общем объединены в такие большие группы, как организационно-распорядительные, просительные и уведомительно-просительные, справочно-информационные, отчетно-регистрационные и исполнительные, судебно-следственные [Гауч 2013: 223]. Определяя жанровые особенности калмыцких документов, мы обращались непосредственно к результатам их исследований, в частности к классификации.

Здесь уместно будет сказать, что фонды Национального архива Республики Калмыкия (далее - НА РК) также содержат богатый материал по русскому деловому письму XVIII-XIX вв. и ждут своих исследователей. Они оригинальны тем, что содержат информацию о восточной цивилизации кочевников и изобилуют калмыцкими словами, эквивалентов которым нет в русском языке.

Материалом для нашего исследования послужили документы из фондов Национального архива Республики Калмыкия. Наиболее богатым деловыми текстами, относящимися к периоду Калмыцкого ханства, является фонд И-36. Он состоит из 437 дел, в которых хранятся деловые документы на калмыцком языке, свидетельствующие об активном развитии государственного делопроизводства у калмыков того времени.

Содержание дел этого и других фондов находится в стадии изучения, поэтому определенный нами в данной статье жанровый состав в будущем будет, вероятно, расширяться и уточняться.

Находясь в начальной стадии исследования этого вопроса, мы не имеем возможности давать окончательную классификацию калмыцких документов, однако можем дать первую информацию о выявленных нами документах.

В зависимости от функциональной направленности мы определили следующие группы документов, которые на основе проведенного анализа можно отнести к выделяемым нами самостоятельным жанрам калмыцкой деловой письменности: са̄ǰiyin bičiq, zarčim (иаажсчин бичг) 'правовые уложения’, amur yabuxu bičiq (амр йовх бичг) 'увольнительное письмо', ayiladxal bičiq (әәлдхл бичг) 'доношение', erelge (эрлh) 'прошение', andaүār (андhap) 'присяга', tō (mo) 'реестр' и самый многочисленный по числу представленных документов жанр bičiq (бичг) 'эпистолярий’

В ходе изучения вышеуказанных групп документов мы обнаружили, что название документа обычно прописано в начале его текста. Однако это наблюдается не всегда. Иногда название документа встречается в самом тексте или его конце. Иногда при отсутствии названия в калмыцком тексте он присутствует в русском переводе.

\section{Цаажсин бичг - Правовое уложение}

Правовые уложения, которыми пользовались калмыки, находясь на территории России, - законодательные памятники, широко известные монголоведам по трудам российских историков. Среди них - «Ик цааж» ('Великое уложение'), созданное в 1640 г. на съезде монгольских и ойратских князей на территории Джунгарии. До наших дней дошли списки этого уложения с добавлениями указов Галдан хун-тайджи [Их Цааз 1981].

Законодательный сборник «Шажн төрин зарчм» ('Духовные и светские законы’) был составлен при калмыцком хане Дондук-Даши в середине XVIII в. с учетом общемонгольских традиций и новых экономических и политических условий, в которых пребывали калмыки на территории России в тот период [Голстунский 1880].

В 1822 в. представителями калмыцкой знати был составлен новый свод, известный как Зинзилинские постановления, по результатам их собрания, проходившего в урочище Зинзили [Позднеев 1892].

Кроме этих известных правовых уложений, функционировали и другие, в большей части неизвестные нам, правовые источники. Так, в НА РК нами обнаружен исторический документ под названием «Хойр түмн цергин зарчм» ('Уложение 20-тысячного войска'), который был составлен 20 ноября 1769 г. командным составом калмыцкого 20 -тысячного войска, участвовавшего в составе русской армии в русско-турецкой войне 1768-1774 гг. Этот документ представляет собой письменный памятник военного права калмыков. Памятник описан и введен нами в научный оборот [Гедеева 2002]. 


\section{Амр йовулх тамһ бичг - Увольни- тельное письмо (Вольная грамота)}

Увольнительное письмо как разновидность делового текста обладает рядом характеристик, имеет правовую значимость, отражает определенную ситуацию. Показателем этого является увольнительное письмо, выданное в 1777 г. нойоном Ценден-Дорджи манджику Гаван Шарабу [НА РК. Ф. И-35. Оп. 1. Д. 113. Л. 29].

Документ имеет определенную структуру, характерную для подобного жанра. В самом его начале сообщается, что это копия: köböün bičiq (көвүн бичг) букв. 'сыновнее письмо', затем идет его название - cenden dorjiyin bičiq tamaya (Цендн Доржчин бичг maмh) 'грамота (букв. 'письмо-печать') Цендена Дорджи'. Далее сообщается цель документа - дарование свободы - beyei čin beyedüčin öqči amur yabuulxu (бийичн бийдчн өгч амр йовулх) 'отправить на свободу, предоставив себя самому’, затем описывается причина такого решения - urida

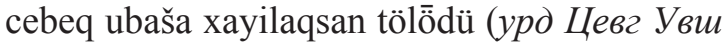
хәәлсн (хәәрлсн?) төләд) 'поскольку Цебек-Убаши ранее соблаговолил', указывается поддержка его со стороны официальных лиц - toqmidiyin mededegeyin dēre. bayai yabang. gendün ubaša. basa čigi gereči bolǰi (Тогмидин меддгин деер Баһа Һавн, Гендн Увш бас чигн герч болжс) '[судья] Тогмид об этом знал, и, кроме него, Бага Гаванг и Гендун Убаша являются свидетелями'.

Резюмируя аргументы, нойон сообщает, что согласен со всеми, в связи с чем выдает данный документ — bi čigi zöbšōji bičiq tamaya öqböbi (би чигн зөвшәжс бичг тамh өгвв).

Деловой язык текста отличается наличием таких слов и сочетаний, как: köböün bičiq (көвүн бичг) 'копия документа (букв. сыновний документ)', bičiq tamaya (бичг mash) 'письмо-печать (грамота)', gereči boloxu (герч болх) ‘быть свидетелем’, zöbšōkü (зөвшәх) 'разрешить', хаyirlaxu (хәәрлх) 'жаловать, соблаговолить’ и т. д.

Таким образом, данное увольнительное письмо (вольная грамота), представляет собой образцовый текст жанра калмыцкого делового письма.

\section{Әәлдхл бичг -Доночение}

Доношение - это одна из разновидностей документов в российском делопро- изводстве, служившая для осуществления передачи сведений в вышестоящие органы. Автор документа должен был обязательно изложить все основания и обстоятельства дела, а также выразить свое мнение, без чего документ не принимался. Такой документ, название которого на калмыцком языке ayiladxal bičiq (дәлдхл бичг 'доношение'), в 1771 г. подал в губернскую канцелярию нойон Ценден-Дорджи. В нем он сообщает о том, что передает в канцелярию печать умершего нойона Цебек-Убаши, чтобы не произошло подлога документов, поскольку эта печать принадлежала нескольким поколениям нойонов [НА РК. Ф. И-35. Оп. 1. Д. 113. Л. 33].

Поскольку объем документа небольшой, то приводим здесь полностью этот образцовый текст доношения:

dēdü tede yeke öröšōgōi ezeni gübariski kancalār-tu:: : ::

ayiladxal bičiq bariba.. noyon cebeq ubašiyin tamayayigi kancalār-tu baribabi.. učirni ömnöki xoyor yurban önggöröqsön

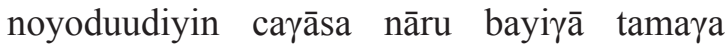
bolonoi.. tere tölö:dü ene tamaya mandu bayidaq bolxuna.. xuurmaq xuluyayin tamaya yarxu ülü bayinu geküyin tölödü.. kancalār-tu baribā:

yal takā juliyin üker sarayin arban $\gamma$ urbandu bičibe..

Деед Тедн ик өршәһә эзнә гүберск каниларт.

Әәлдхл бичг бәрв. Нойн Цевг Увшин тамһиг каниларт барвв. Учрнь: өмнк хойрһурвн өнгрснн нойдудин иагас нааран бәәһә тамһ болна. Тер төлдд эн тамһ бәәдг бохла, хуурмг-хулхан тамh hарх эс бәәнү гихин төләд каниларт бәрвә. Һал така жсилин үкр сарин арвн һурвнд бичв.

'Перевод 3 доношения присланнаго в астраханскую губернскую канцелярию от дербетева владелца Ценден-Доржи, полученнаго ноября 10 дня 1777 года. Оной губернской канцелярии представляю умершаго владелца Цебек-Убаши печать для хранения во оной канцелярии, дабы не могло произойти подложных уволнительных писем, ибо оная посмерти предков еже (?) оставалась в улусе; у писма печать красная, писано месяца укер 13, то есть ноября ... дня 1777 года. (Переводил переводчик Ипат Федотов)' 
В том же деле есть доношение Ценден-Дорджи также в губернскую канцелярию о том, что он выдал увольнительное письмо чашечнику, манджику Гаван Шарапу и что к доношению прилагает копию увольнительного письма [НА РК. Ф. И-35. Оп. 1. Д. 113. Л. 27].

\section{Эрль - Прошение}

Прошение представляет собой письменное ходатайство о чем-нибудь, просьбу по официально установленной форме. Так, в архиве мы выявили исторический документ 1822 г., представляющий собой коллективное письмо пяти калмыцких судей (дербетовских судей Джамба гелюнга и Култуша, хошутского судьи Оргочки, яндыковского судьи Занбо и багацохуровского судьи Чидан Убаши), адресованное главному приставу Калмыцкой степи А. В. Каханову с просьбой ходатайствовать перед вышестоящими инстанциями о разрешении калмыкам создать кодекс законов по своим традициям с учетом современных тому периоду требований. Обращение судей предваряется описанием драматического положения калмыцкого общества в сфере судопроизводства, при котором калмыки, не знающие русского языка и российских законов, не могут себя защитить и в результате жестокого с ними обращения в губительных для вольнолюбивых кочевников тюрьмах еще до суда умирают [НА РК. И-1. Оп. 1. Д. 182. Л. 11-14; Гедеева 2019б].

К жанру прошения также можно отнести письмо 1778 г. дербетовского нойона Ценден-Дорджи астраханскому губернатору Ивану Варлаамовичу Якоби, в котором он описал хозяйственно-экономическое положение его кочевий, связанное с колонизацией калмыцких территорий [НА РК. Ф. И-35. Оп. 1. Д. 113]. Нойон Ценден-Дорджи сильно обеспокоен тем, что калмыцкая земля все больше урезается и отдается жителям станиц под хлебопашество и сенокосные угодья, строятся хутора, мельницы, хозяева которых не подпускают кочевников близко к своим новым землям. Доношение подано в 1778 г., через 7 лет после откочевки большей части калмыков из России на историческую родину в Центральную Азию. В письме наглядно отразилась одна из причин ухода калмыков: сокращение территории кочевий и пастбищ. Нойон просит разобраться в этой проблеме и принять соответствующее решение по урегулированию спорных территорий [Гедеева 2019а].

\section{Андһар - Присяга}

Одним из жанров калмыцкой деловой письменности XVII-XIX вв. является присяга andaүār. Судя по выявленным нами архивным материалам, слово andaүār означает несколько видов присяги [Гедеева 2018: 70-75]. Один из них - очистительная присяга, проводимая во время судебного разбирательства по причине отсутствия явных доказательств, освобождающая ответчика от ответственности. В тексте такой присяги подозреваемый клянется в своей невиновности, призывая божества в свидетели, и заявляя о готовности понести божью кару, если он совершил преступление. Данный вид присяги упоминается в исторической литературе в связи с описанием калмыцкого судопроизводства в прошлые столетия [Георги 1799; Паллас 1809; Смирнов 1999; Рязановский 1931; Голстунский 1880; Их цааз 1981; Гедеева 2018].

Так, П. Смирнов описывает сцену судебной присяги, когда следователь, ведущий дело, приглашает присяжного гелюнга андагарун багши, который возлагает на голову присягающего после слов клятвы изображение божества. Текст клятвы зачитывает сам гелюнг, а подозреваемый за ним повторяет [Смирнов 1999: 140-141].

Второй вид присяги зачитывался во время судебного разбирательства свидетелем, если таковой имелся. Он зачитывал текст присяги и клялся, что говорит правду о том, что знает. Во всех выявленных нами текстах присяги в свидетели призывается Будда Шакьямуни, при этом его образ прикладывается к голове [РГАЛИ. Ф-527. (Фонд В. Хлебникова). Оп. І. Ед. хр. 289].

Еще один документ данного жанра был выявлен нами в фондах НА РК. Это текст присяги нойона Дондук-Омбо при назначении его главным управителем калмыцкого народа в 1735 г. на верность императрице Анне Иоановне и ее наследникам. Присяга верности обычно зачитывалась в переломные моменты в общественной жизни, например при смене власти [НА РК. И-36. Оп. 1. Д. 11. Л. 114].

Присяга, примиряющая две враждующие стороны - это еще один из видов при- 
сяги, текст которой обнаружен нами в фондах калмыцкого архива [НА РК. И-36. Оп. 1. Д. 373. Л. 654]. Выявленный текст присяги посвящен примирению нойонов Еремпеля и Бамбара, известных владельцев, игравших видную роль в общественно-политической жизни калмыков. Оба они имели спор по приданому сестры Бамбара, разведенной жены Еремпеля.

Таким образом, выявленные материалы свидетельствуют о том, что жанр андһар имеет также свои подвиды.

\section{To- Реeсmp}

Изучая документы калмыцких князей, адресованные астраханской администрации, мы обнаружили немало реестров списков предметов, скота, имен людей, которые составлялись в результате грабежа, разбоя, спорных вопросов об имуществе. Очень часто встречается перечень предметов домашней утвари, постельных принадлежностей, одежды, украшений, военного оружия, конского снаряжения и т. д., которыми пользовались калмыки того времени. В настоящее время многие названия забыты и не зафиксированы в имеющихся словарях, что делает их ценным материалом для лингвистов. Правила описи одежды или любых других предметов предполагали название материала и форму изделия, что сейчас нам предоставляет интересный этнографический материал, свидетельствующий об эстетических вкусах калмыцкой знати. При перечне скота обычно подробно описывается масть лошадей. При перечислении имен людей, которых увели разбойники или враждующие владельцы, обычно называются их рода, что представляет также очень ценный материал для этнографов.

Таким образом, изучение подобных документов крайне важно для исследователей разных областей науки.

\section{Бичг - Эпистолярий}

Основная часть сохранившихся памятников калмыцкой деловой письменности представляет собой деловые эпистолярные тексты, отражающие письменное общение калмыцких ханов, князей и судей с российской администрацией. Письма содержат информацию о политической, военной, хозяйственной, судебной жизни калмыков. В зависимости от их содержания деловые письма условно можно разделить на официальные и неофициальные. Официальные письма отличаются строгостью и лаконичностью изложения проблемы. В деловых, но неофициальных письмах адресант интересуется здоровьем адресата и его семьи, выражает поддержку его успехам, каким-то радостным событиям, выражает сочувствие в связи с болезнью адресата и т. д. Стиль речи в письме преобладает разговорный, нежели официальный. Содержание часто бывает эмоциональным, когда адресант выражает удивление, раздражение, порой возмущение. Тогда в тексте присутствуют фразы, выражающие вопрос (teyime bišiyu 'разве не так') или удивление (alang bolōd 'удивившись') и т. д.

Тексты характеризуются определенными этикетными формулами, личностной ориентированностью, многотемностью. Письма, составленные в разные исторические периоды, отличаются своей структурой, реквизитами, формулировками, стилем изложения и т. д. Это зависело как от личности адресанта, так и от правил оформления документов в разные периоды. Так, письма хана Аюки, адресованные астраханскому губернатору, коротки и лаконичны, в них излагается только суть письма. Редко встречаются какие-либо личные просьбы, в основном требования выдать то, что полагается от государства по договоренности, например, жалование, продукты, а также все, что требуется для военных целей.

Письма последующих ханов, князей, адресованные российской, в частности астраханской, администрации обрамлены формулами вежливости, завершаются эти письма словами: tan-du inagi küseqci.. ubasa (Танд иньгиг күсгч Уви) 'Вашего приятства снискатель', kezē biši zakāyār bayidaq noyon yandaq (Кезә биш закаһар бәәдг нойн Яндг) 'Всегда по повелениям поступающий владелец Яндык', ürgülǰi-dü xayiri küsüqči cenden dorji (Үрглжсу хәәр күсгч Цендн Дорж) 'Всегда милости вашей снискатель Ценден Дорджи’.

В архиве иногда встречаются черновики писем представителей астраханской администрации, направленные калмыцким адресатам. По их переписке можно судить об их дружеских отношениях. Но вместе с тем письма остаются деловыми по содержанию, 
и, если излагается несколько вопросов, то обычно они нумеруются как цифрами, так и словами хоуоr dügēr üge 'второй вопрос

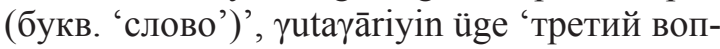
poc', dötögöriyin üge 'четвертый вопрос'.

Непременным реквизитом калмыцких документов и, в частности, деловых писем, были печати адресантов, которые достойны отдельного исследования.

\section{Заключение}

Деловая письменность, развиваясь в системе калмыцкого языка, активно обслуживала сферу делопроизводства. Начиная c XVII в. в ходе дипломатических, военных, экономических отношений с Россией калмыками осваивалась система правил российского делопроизводства. При этом калмыки сохраняли основы традиционно-

\section{Источники}

НА РК - Национальный архив Республики Калмыкия

РГАЛИ - Российский государственный архив литературы и искусства

\section{Литература}

Бембеев, Асирова 2009 - Бембеев Е. В., Асирова H. Д. К вопросу о семантике пространственных послелогов калмыцкого языка XVIII в. (на материале исторических писем) // Вестник Калмыцкого института гуманитарных исследований РАН. 2009. № 2. С. 76-82.

Буслаев 1858 - Буслаев Ф. И. Опыт исторической грамматики русского языка: Уч. пособ. для преподавателей: Ч. 1-2 / сост. Ф. Буслаевым. М.: Унив. тип., 1858. Ч. 1: Этимология. [12], XL, 244 с. Ч. 2: Синтаксис. X, [2], 428 с.

Гауч 2013 - Гауч О. Н. Жанровое своеобразие организационно-распорядительных документов деловой письменности XVIII века (на материале ТФГАТО). // Научный диалог. Филология. № 5(17). Тобольск. 2013. C. 221-233.

Гедеева 2002 - Гедеева Д. Б. «Уложение 20-тысячного войска» как источник по изучению военного права калмыков XVIII в. // VIII междунар. конгресс монголоведов (г. Улан-Батор, 5-12 августа 2002 г.). Доклады российской делегации. М.: ИВ РАН, 2002. C. 18-21.

Гедеева 2018 - Гедеева Д. Б. О судебной присяге в калмыцком судопроизводстве XVII- го этикета письменного делового общения, создавая своеобразие калмыцкой деловой письменности.

В истории калмыцкого языка особое место занимает XVIII в., период функционирования Калмыцкого ханства, когда наблюдается наиболее активный процесс развития делопроизводства и, соответственно, развития официально-делового стиля в языке. Появление новых видов документов в процессе калмыцко-русских отношений способствовало обогащению словарного запаса языка, появлению новых фраз, оборотов, речевых клише и т. д.

Работа по выявлению новых источников продолжается, окончательные выводы по количеству разновидностей калмыцких документов еще впереди.

\section{Sources}

National Archive of the Republic of Kalmykia. Russian State Archive of Literature and Art.

XVIII вв. // Проблемы этнической истории и культуры тюрко-монгольских народов. 2018. Вып. 5. С. 70-75.

Гедеева 2019а - Гедеева Д. Б. О письме дербетовского нойона Ценден Доржи астраханскому губернатору И. В. Якоби (1778 г.) // Бюллетень Калмыцкого научного центра PAH. 2019. № 3. C. 36-47.

Гедеева 20196 - Гедеева Д. Б. Письмо пяти судей как источник для изучения судопроизводства калмыков в XIX в. // $\mathrm{MoH}^{-}$ головедение. 2019. № 2. C. 240-256. DOI: 10.22162/2500-1523-2019-2-240-256.

Георги 1799 - Георги И. Г. Описание всех обитающих в Российском государстве народов. В 4 частях. Часть четвертая. СПб: Имп. Академия наук, 1799. 385 с.

Голстунский 1880 - Голстунский К. Ф. Монголо-ойратские законы 1640 года, дополнительные указы Галдан хун тайджи и законы, составленные для волжских калмыков при калмыцком хане Дондук-Даши. СПб.: Тип. Имп. Акад. наук, 1880. 163 с.

Городилова 2018 - Городилова Л. М. Ландшафтная лексика в деловой письменности Приенисейской Сибири XVII - начала XVIII в. // Филологические науки. Вопросы 
теории и практики. Тамбов: Грамота, 2018. № 4. Ч. 2. С. 340-345.

Их цааз 1981 - Их цааз («Великое уложение»). Памятник монгольского феодального права XVII в. (Транслит., пер., введ. и коммент. С. Д. Дылыкова). М.: Вост. лит., 1981. 181 с. Кокшаева 2011 - Кокшаева Н. О. Языковые особенности эпистолярного наследия калмыцкого хана Дондук-Даши (середина XVIII в.). Элиста: Издат. дом «Герел», 2011. $189 \mathrm{c}$.

Майоров 2019 - Майоров А. П. Сверхтекст в забайкальской деловой письменности XVIII в. как источник реконструкции региолекта того времени // Известия Южного федерального университета. Филологические науки. 2019. № 3. C. 34-45.

Никитин 2016 - Никитин О. В. Изучение языка памятников русской деловой письменности в середине - второй половине XX века: социолингвистический аспект // Вестник Вологодского государственного университета. Серия: Гуманитарные и общественные науки. 2016. № 1. С. 67-71.

Паллас 1809 - Паллас П. С. Путешествия по разным провинциям Российской империи. Ч. 1. СПб.: Имп. Академия наук, 1809. 657 с.

Позднеев 1892 - Позднеев А. М. Калмыцкая

\section{References}

[A Historical Russian Grammar]. Teacher's manual. Vols. 1-2. F. I. Buslaev (comp.). Moscow: Imperial Moscow University, 1858. Vol. 1: Etymology. 244 p. Vol. 2: Syntax. 428 p. (In Russ.)

[Ikh Tsaaz: The Great Code of Laws. Monument of $17^{\text {th }}$-Century Mongolian Feudal Law] S. D. Dylykov (transl., introd., etc.). Moscow: Vostochnaya Literatura, 1981. 181 p. (In Russ.)

Bembeev E. V., Asirova N. D. Semantics of $18^{\text {th }}$ century Kalmyk spatial postpositions revisited: a case study of historical letters. Bulletin of the Kalmyk Institute for Humanities of the RAS (Oriental Studies). 2009. No. 2. Pp. 76-82. (In Russ.)

Filin F. The ancient Rus': language of official writings revisited. In: [Questions of Philology]. Jubilee coll. Moscow: Lenin Moscow State Pedagogical Institute, 1974. Pp. 31-37. (In Russ.)

Gauch O. N. Genre diversity of organizationaladministrative documents of XVIII century's formal writing (based on materials of Tobolsk хрестоматия: для чтения в старших классах калмыцких народных школ. СПб.: Тип. Имп. акад. наук, 1892.172 с.

Попов 2017 - Попов Е. Ю. Синонимические связи единиц юридической лексики в документах Приенисейской Сибири XVII в. // Филологические науки. Вопросы теории и практики. Тамбов: Грамота, 2017. № 9 (75) в 2-х ч. Ч. 1. С. 152-154.

Рязановский 1931 - Рязановский А. Монгольское право (преимущественно обычное). Харбин: Тип. Н. Е. Чинарева, 1931. 352 с.

Смирнов 1999 - Смирнов П. Путевые заметки по Калмыцким степям Астраханской губернии. Элиста: Калм. кн. изд-во, 1999. 247 с.

Соколова 1957 - Соколова M. А. Очерки по языку деловых памятников XVI в. Л.: Издво ЛГУ, 1957. 191 с.

Сусеева 2003 - Сусеева Д. А. Письма хана Аюки и его современников (1714-1724 гг.): опыт лингвосоциологического исследования. Элиста: АПП «Джангар», 2003. 384 с.

Филин 1974 - Филин Ф. О языке деловой письменности в Древней Руси // Вопросы филологии: К семидесятилетию со дня рождения и пятидесятилетию научно-педагогической деятельности профессора А. Н. Стеценко. М.: МГПИ им. В. И. Ленина, 1974. С. 31-37.

Branch of Tyumen Region State Archive). Nauchnyi dialog. Filologiya. 2013. No. 5(17). Pp. 221-233. (In Russ.)

Gedeeva D. B. Codes of the Twenty Thousand Army as a research source on $18^{\text {th }}$-century Kalmyk military law. In: [The Eighth International Congress of Mongolists]. (Ulaanbaatar; August 5-12, 2002). Reports of Russian scientists. Moscow, 2002. Pp. 18-21. (In Russ.)

Gedeeva D. B. Considering the letter of Derbet Noyon Tsenden Dorji to the Astrakhan Governor I. V. Jacobi (1778). Bulletin of the Kalmyk Scientific Center of the RAS. 2019. No. 3. Pp. 36-47. (In Russ.)

Gedeeva D. B. Kalmyk judicial proceedings, $17^{\text {th }}$ $18^{\text {th }}$ centuries: court oath revisited. In: [TurkoMongols: Issues of Ethnic History and Culture]. 2018. Vol. 5. Pp. 70-75. (In Russ.)

Gedeeva D. B. The Letter of Five Judges as a source for studies of $19^{\text {th }}$-century judicial proceedings of the Kalmyks. Mongolian Studies. 2019. No. 2. Pp. 240-256. (In Russ.) DOI: 10.22162/25001523-2019-2-240-256. 
Georgi J. G. [Description of All Peoples Inhabiting the Russian Empire]. In 4 vols. Vol. 4. St. Petersburg: Imperial Academy of Sciences, 1799. 385 p. (In Russ.)

Golstunsky K. F. [Mongolian-Oirat Laws of 1640, Additional Decrees of Galdan Hong Tayiji, and Laws Compiled for the Volga Kalmyks during the Reign of Khan Donduk-Dashi]. St. Petersburg: Imperial Academy of Sciences, 1880. 163 p. (In Russ.)

Gorodilova L. M. Landscape vocabulary in business written language of Yenisei Region Siberia of the XVII - the beginning of the XVIII century. Philological Sciences. Issues of Theory and Practice. 2018. Vol. 4. No. 2. Pp. 340-345. (In Russ.)

Kokshaeva N. O. [Epistolary Heritage of the Kalmyk Khan Donduk-Dashi, Mid-18 Century: Language Features]. Elista: Gerel, 2011. 189 p. (In Russ.)

Mayorov A. P. Supratext in Trans Baikal business written texts of the XVIII century as a source of reconstruction of the regional dialect of that time. Proceedings of Southern Federal University. Philology. 2019. No. 3. Pp. 34-45. (In Russ.)

Nikitin O. V. Studying the language of documents of Russian business literature in the middle second half of the $20^{\text {th }}$ century: sociolinguistic aspect. Bulletin of Vologda State University. Series Humanities and Social Sciences. 2016. No. 1. Pp. 67-71. (In Russ.)

Pallas P. S. [Journeys to Different Provinces of the Russian Empire]. Vol. 1. St. Petersburg: Imperial Academy of Sciences, 1809. 657 p. (In Russ.)

Popov E. Yu. Synonymic relations between juridical vocabulary units in the documents of Yenisei region Siberia of the XVII century. Philological Sciences. Issues of Theory and Practice. 2017. Vol. 9 (75). No. 1. Pp. 152-154. (In Russ.)

Pozdneev A. M. [Kalmyk Chrestomathy: Reader for Senior Pupils of Kalmyk Public Schools]. St. Petersburg: Imperial Academy of Sciences, 1892. 172 p. (In Kalm.)

Ryazanovsky A. [Mongolian (Customary) Law]. Harbin: N. E. Chinarev, 1931. 352 p. (In Russ.)

Smirnov P. [Across Kalmyk Steppe of Astrakhan Governorate: Travel Notes]. Elista: Kalmyk Book Publ., 1999. 247 p. (In Russ.)

Sokolova M. A. [Essay on the Language of $16^{\text {th }}$-Century Official Writings]. Leningrad: Leningrad State University, 1957. 191 p. (In Russ.)

Suseeva D. A. [Letters of Khan Ayuka and His Contemporaries (1714-1724): a Linguosociological Study]. Elista: Dzhangar, 2003. 384 p. (In Russ.) 